\title{
Mapping Inuinnaqtun: The Role of Digital Technology in the Revival of Traditional Inuit Knowledge Ecosystems
}

\author{
Brendan Griebel * and Darren Keith
}

check for updates

Citation: Griebel, B.; Keith, D. Mapping Inuinnaqtun: The Role of Digital Technology in the Revival of Traditional Inuit Knowledge Ecosystems. ISPRS Int. J. Geo-Inf. 2021, 10, 749. https://doi.org/ $10.3390 /$ ijgi10110749

Academic Editor: Wolfgang Kainz

Received: 30 August 2021

Accepted: 27 October 2021

Published: 5 November 2021

Publisher's Note: MDPI stays neutral with regard to jurisdictional claims in published maps and institutional affiliations.

Copyright: (c) 2021 by the authors. Licensee MDPI, Basel, Switzerland. This article is an open access article distributed under the terms and conditions of the Creative Commons Attribution (CC BY) license (https:// creativecommons.org/licenses/by/ $4.0 /)$.
Pitquhirnikkut Ilihautiniq/Kitikmeot Heritage Society, P.O. Box 2160, Cambridge Bay, NU X0B 0C0, Canada; dkeith@kitikmeotheritage.ca

* Correspondence: bgriebel@kitikmeotheritage.ca

\begin{abstract}
The term Inuinnaqtun is often used in reference to a dialect of Inuktut spoken by Inuinnait (Copper Inuit) of the Central Canadian Arctic. The broader meaning of Inuinnaqtun, however, is to speak, to create, to practice, to do, to think, to be, like an Inuinnaq (a human being). Inuinnaqtun was once its own robust ecosystem, with Inuinnait physically immersed in a landscape and way of life that nourished a fluent and full language, supported human relationships, and maintained a sophisticated body of cultural knowledge. The Inuinnait journey into the 21st century has challenged the practice of Inuinnaqtun, along with the connectivity of its ecosystem. How can an integrated Inuinnaqtun ecosystem be restored in contemporary Inuinnait society? In this paper, we outline the decade-long development of a digital mapping program to document traditional forms of engagement between Inuinnait people, language and land, and facilitate the continued circulation of knowledge that underlies these relationships. In reviewing its various successes and challenges, we critically question digital technology's ability to digitally represent Inuinnaqtun ontology, in addition to the role that digital technologies can play in facilitating the local relocation of knowledge, objects and relationships dispersed into global contexts.
\end{abstract}

Keywords: Inuinnait; Inuinnaqtun; cybercartography; digital return; toponymy; multi-media cartography; digital heritage

\section{Introduction}

The transition of Inuit into the 21st century has tested the fabric of a lifeway that has long been honed through geographic isolation and cultural insularity. For centuries, Inuit throughout the North American Arctic lived according to seasonal migration within a defined, regional landscape (see [1] (pp. 33-37), [2] (pp. 410-434) for the specifics of migration and land-use among Inuinnait), and developed a high level of cultural synchronicity with a specific environment. Inuit were part of a larger ecosystem, relying on their immediate surroundings for the tools they made, the clothes they wore, and the food they ate. This close relationship went beyond physical engagement, with language, beliefs and spirituality also being finely attuned to the natural world.

The bridged cultural and environmental ecosystems of Inuit changed dramatically upon contact with Euro-American people and their traditions. While impactful crosscultural encounters occurred at different times and to varying degrees depending on geographic location, almost all Inuit had relocated to urban settlements by the mid-1960s as a direct result of this change. The rapid transition from land to town has made it more difficult to sustain the culture, language and beliefs that are so deeply interwoven with daily engagement with the natural environment. This article will consider how one regional group of Inuit, called Inuinnait, were impacted by these changes to their lifestyle.

Inuinnait are a culturally distinct (cf. [3] (pp. 20-21)) population of Inuit who live in the Central Canadian Arctic, in the territory of Nunavut (see Figure 1). The term Inuinnait quite literally means 'the people' in the Inuinnaqtun language. Over the last two decades, the use of 'Inuinnait' has grown in popularity as a collective name to replace 'Copper 
Eskimo/Inuit', a term coined by the explorer and ethnologist Vilhjalmur Stefansson in the early 20th century due to the group's distinct use of the naturally sourced copper as metal for their tools [4]. Inuinnait have long self-identified according to the names of localized family groupings dispersed across the region prior to settlement in urban communities (see Figure 2).

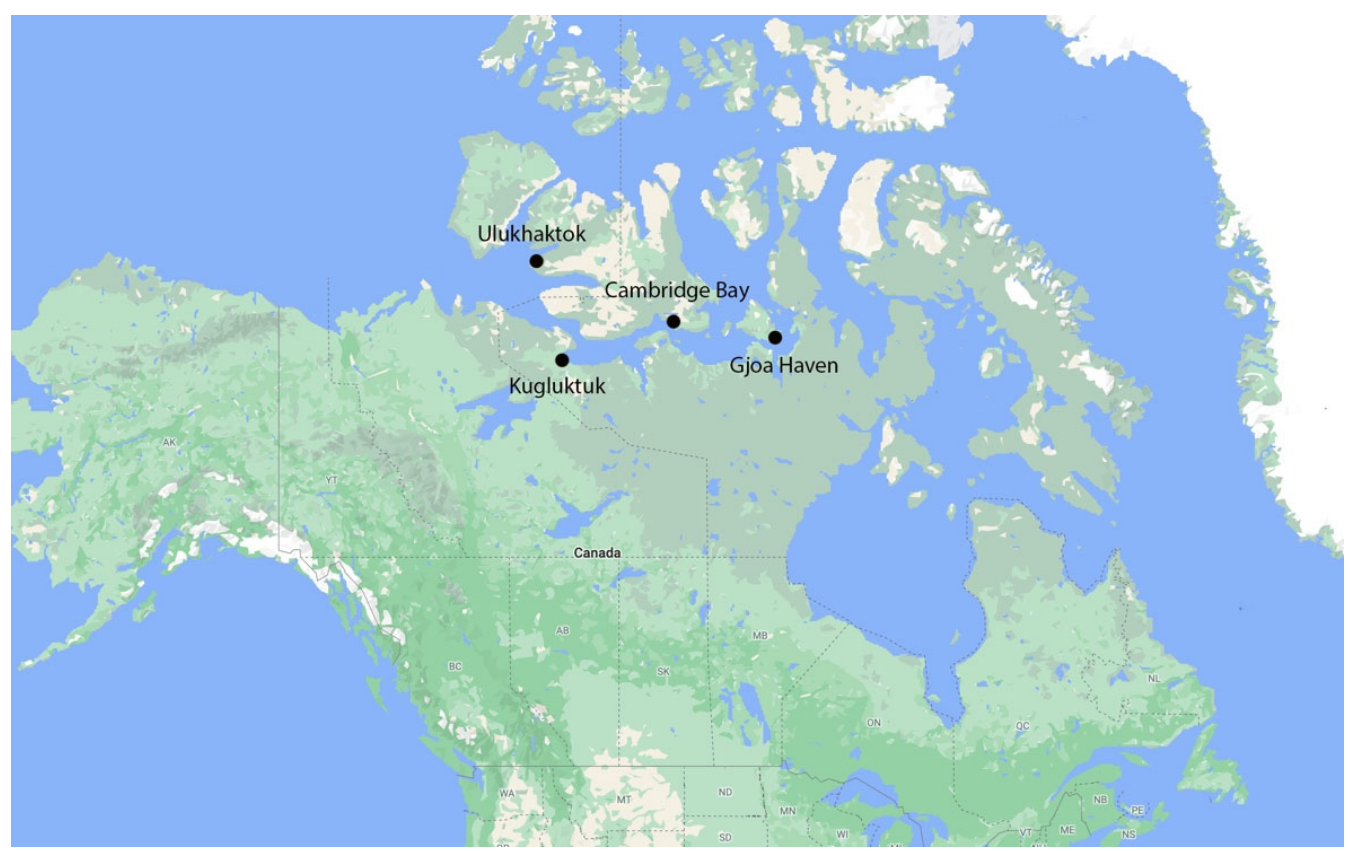

Figure 1. An overview of the Central Canadian Arctic indicating the positions of the four contemporary Inuinnait communities of Cambridge Bay, Ulukhaktok, Kugluktuk, and Gjoa Haven, located on and around Victoria Island and King William Island. Basemap source: Google Maps.

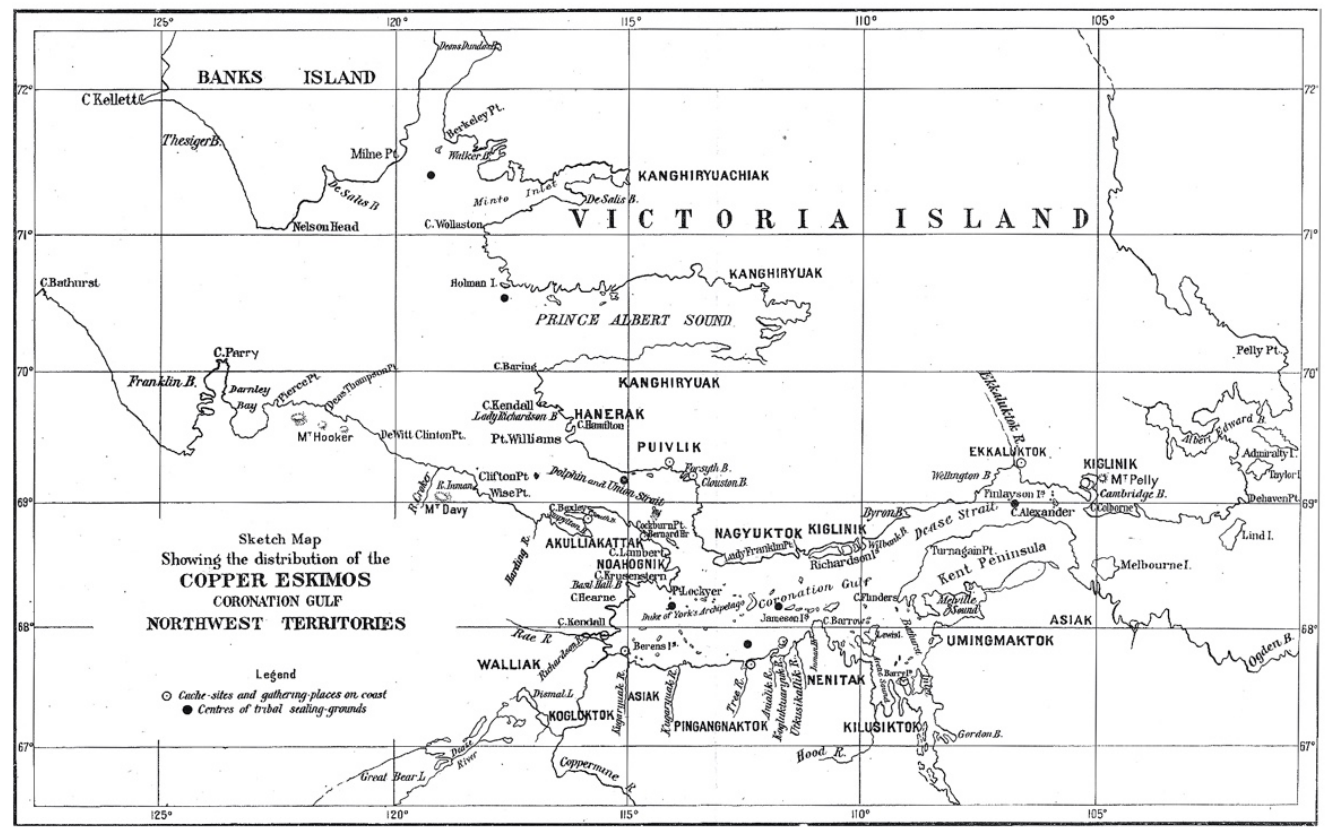

Figure 2. I A sketch map of the Inuinnait region in the Coronation Gulf surrounding Victoria Island in the Central Canada Arctic. Created by anthropologist Diamond Jenness for a 1921 ethnography [5] (287), this map provides the names of Inuinnait family groups who made up a total population of roughly 800 individuals at the time of Jenness' census work. 
Located in the heart of the notoriously inaccessible Northwest Passage, Inuinnait were among the last groups of Inuit in the Canadian Arctic to engage with western culture and undergo significant lifestyle changes as a result.

A rapid transition to new materials, technologies, and worldviews has characterized the last century for many Inuit groups, and this was no different for the Inuinnait. The relative lateness of their contact with Euro-Americans, which began around 1910, was accompanied by a strong awareness of the degree of change awaiting the group as they negotiated the arrival of foreign people, ideas, and materials. In 1921, the anthropologist Diamond Jenness outlined the various impacts of western society on Inuinnait since initial contact occurred roughly a decade earlier, noting deep ramifications across all aspects of Inuinnait culture-from material possessions, diet, and hunting preferences, to migration routes and social/religious practices [6]. By 1924, Knud Rasmussen of the Danish Fifth Thule Expedition-to be discussed later in this paper-was documenting the language and lifeways of Inuinnait with an understanding that his recordings would serve to help rebuild Inuinnait culture upon its inevitable collapse [7].

Concern regarding the change in and loss of what many refer to as 'traditional' Inuinnait knowledge and practices continues into the present, particularly in relation to digital technologies. Inuit have been using digital media as tools for communication since the earliest days of the Internet [8]. The Internet's widespread arrival to northern communities in the 1990s was greeted not only as a way to bring Inuit together across the Arctic's geographic expanse, but also to amplify their voices and unique identity across the world [8] (pp. 54-56), [9] (p. 115). However, the prospect of an Internet-based future for Inuit was also tempered by anxiety about its potential impacts on their way of life, with facilitated access to global culture and resources seen as a surefire way to further unravel the Inuit social fabric $[10,11]$. To this day, the study of digital media use among Inuit remains split by the debate of assimilation vs. appropriation: one which asks "whether Inuit can appropriate digital media in order to preserve their culture or whether the technology will cause Inuit to be assimilated into a dominant global culture" [12] (p. 228). The question is whether the specific affordances of a technology - what it allows people to do, or prevents them from doing - has a dramatic impact on shaping the ways that Inuit culture and knowledge exist on-line.

This paper documents Pitquhirnikkut Ilihautiniq/Kitikmeot Heritage Society's (PI/KHS) ongoing research program to map and mobilize Inuinnaqtun ecosystems through an online digital platform development. PI/KHS is an Inuit-directed, non-profit organization based in Cambridge Bay, Nunavut, dedicated to the preservation and renewal of Inuinnait knowledge, language and culture across the four contemporary Inuinnait communities. Research and programming at the society are guided by an Inuinnaq Director and Board, who work closely to ensure that the organization's activities align with the cultural, linguistic, and heritage priorities in the community.

In 2005, PI/KHS began to consider a digital future for Inuinnait knowledge, collected as part of its cultural research program. This transition was motivated by multiple reasons, including the decreasing number of language experts and elders with first-hand experience of a land-based lifestyle, the relative impermanence of existing analog and textual recordings of Inuinnait knowledge, and the need for greater accessibility of these resources among Inuinnait, especially younger generations. As an organization, we were deeply involved in exploring the role that digitization could play in efforts to document and preserve Inuit language, culture and history. Over the course of developing multiple digital platforms using the Nunaliit cybercartographic framework, we have explored various ways in which the Inuinnait ecosystem could be represented in a digital environment. Throughout this process, we were often faced with the same dilemma of assimilation vs. appropriation, namely: can a customized Inuinnait digital platform support the structure and understanding of an online Inuinnaqtun ecosystem? Digital environments can depict specific objects, places and experiences-even enhance them through multimedia content-but at what cost to other valuable cultural context and information? 


\section{Materials and Methods}

While there is a vast existing academic literature on cultural ecology in the Canadian Arctic, the concept of an Inuinnaqtun ecosystem underlying PI/KHS' work is one that stems directly from the experience and intellectual traditions of Inuinnait elders. In retelling their lives, many elders emphasize a story of change: one of being born and raised on the land, then moving into town; one going from deep familiarity and harmony with the environment to being urban-bound. Underlying all of these narratives is the understanding that Inuinnait culture was once deeply embedded and in sync with the natural environment, and that this is where the culture continues to reside, even when its people do not.

Awareness of the disconnect between contemporary Inuinnait communities and traditional culture permeates the stories Inuinnait tell about themselves. There is a common understanding that the Inuinnaqtun ecosystem is not simply a thing of the past, but an enduring cultural state that requires active engagement and maintenance. This is especially the case when living in an urban environment in which English is a dominant language and the growing reliance on technology, values, and priorities external to the culture has further widened the gap between generations. The distance between Inuinnait and their ancestral language and lifeways is not envisioned in terms of 'loss', but rather 'dormancy', with foundational cultural knowledge said to be sleeping, just waiting for new generations to revive it.

To define the Inuinnaqtun ecosystem is to reference a highly complex worldview and way of being that has evolved over centuries of Inuit engagement with their environment. As was demonstrated through Janet McGrath's conversations with Inuit scholar Mariano Aupilarjuk [13], profound theoretical and experiential foundations underlie Inuit ontology, despite the difficulties articulating them outside the cultural traditions in which they are anchored. In searching for a way to explain an Inuinnaqtun ecosystem that is both understandable and relatable to a broader audience, this article focuses on the intricate connections between three of its key components: language, land and people. Each of these concepts will be briefly explored in turn.

The Inuinnaqtun language is a key factor for understanding the broader Inuinnaqtun ecosystem. In addition to its geographic territory (see Figures 1 and 2), Inuinnait culture distinguishes itself from other regional Inuit groups through clothing styles, social practices, and material technologies and, perhaps most importantly, through language. The Inuit language family has a large geographic distribution across the Arctic, which is generally attributed to the rapid spread of common ancestors from Alaska to Greenland roughly 800 years ago. Over the centuries that followed, the common language began to differ in dialect. Inuinnait developed a unique version of the language, shaped specifically according to their lifestyle and surroundings, known as Inuinnaqtun. Like all Inuit languages, Inuinnaqtun has its roots in orality rather than writing. Roman orthography was introduced by early missionaries, but the heart of the language continues to reside in the spoken word.

While Inuinnaqtun refers to a language dialect, it has a broader meaning within the culture: Inuinnaqtun means to speak, to create, to practice, to do, to think, to be, like an Inuinnaq (Inuinnaq meaning a human being). In this sense, Inuinnaqtun refers to a larger cycle in which language not only allows people to name their world, but also to properly function within it. Understanding of the Inuinnaqtun ecosystem is deepened when the concept of language is added to that of land. Inuinnait once lived in a purely Inuinnaqtun environment. Everything in that environment was named: animals, the elements, and natural resources were all layered with rich terminology that was passed along and sustained through constant engagement. Many family groups took their names and social identity from specific geographic landmarks along their seasonal migration routes (see Figure 2). While pre-contact Inuinnait landscapes were not generally recorded through mapping (see exceptions in $[14,15]$ (p. 5), places were intimately known through toponymy. The extensive use of place names allowed Inuinnait to craft a simultaneously personalized and deeply cultured narrative for the visually uniform tundra landscape, 
with travelers often reciting the names of features along the trail to track both their physical progress across the land, and deepen their sense of history and cultural belonging within it [1] (p. 11). In addition to place names, many landscapes also possess oral traditions, which include detailed explanations of a place name's meaning and origins, descriptions of the resources available at a site, or accounts of past events extending from deep history to living memory.

Relationships between people also strongly factor into this ecosystem, both through intricate kinship structures and mentorship to ensure the free-flow and continuance of Inuinnaqtun knowledge. Knowledge of language and land was acquired through observation, listening, and being physically and mentally present among cultural experts. Knowledge transfer was a social process, with each generation working together to prepare individuals for the stages of their lives in which specific skills and insights are required. As articulated by Scott Heyes [16] (pp. 45-46), Inuit knowledge of their environment was transmitted through a "process where people who are capable and knowledgeable in performing select tasks support new learners until their knowledge is sufficient for them to accomplish tasks on their own ... The practical transmission of traditional knowledge through hunting - an ongoing process of instruction and learning-allowed young Inuit to acquire knowledge about the land while on the land". Almost invariably, in such a system, the individuals dispensing culturally specific knowledge belonged to older generations.

Maintaining an ecosystem of language, land and people requires that all three elements are present: a change in one impacts them all. The introduction of Inuinnait to the western world greatly disrupted this ecosystem. The transition from land to town happened quickly. Many Inuinnait had not directly encountered non-Inuit explorers and traders until the mid to late 1910s. By the 1920s, trading posts had moved into the area, encouraging Inuit to leave traditional subsistence hunting for the pursuit of fox furs, which could be sold to posts in exchange for western luxuries. The trading posts were quickly followed by other institutions: the RCMP, Roman Catholic and Anglican churches. In 1951, the region's first residential school was built to physically remove children from their families and language to ensure an education in western ways. When these children returned to their homes, many of them unilingual in English, they found themselves in a world for which they no longer had words to engage with or describe. Leveraging the vulnerabilities of cultural transition, the Canadian Government facilitated the movement of Inuinnait populations off the land and into hastily built settlements where systems of education, health care and social welfare services could be more easily administered [17]. As Inuinnait life adjusted to the realities of settlement, practices associated with living on the land became less used. This, in turn, brought about the gradual disappearance of the highly customized technology, terminology, and social relationships that accompanied these activities. In towns, Inuinnaqtun withdrew from homes and separated from everyday use. Generational divides diverted the experience of the young and old. Sophisticated systems of oral tradition and social knowledge transfer suffered through the breakdown of these relationships.

The question of how to reverse the breakdown of traditional lifeways in a modern era has been an ongoing challenge to Inuit and non-Inuit alike. The early 2000s saw a growing academic movement towards digital technology as a means to document, preserve and revive Indigenous knowledge and language across the Arctic and beyond (see, e.g., [18-20]). While proposed applications were diverse-ranging from computer and archive databasing and GIS mapping to the digital repatriation of museum collections-they were uniformly optimistic about the translation of Indigenous knowledge into new digital media and platforms, citing the potential for more permanent records, increased accessibility within and between remote communities, economic benefits [21], and increased opportunities for marginalized groups to have their voices heard [22]. There was concern that digitized Indigenous knowledge would be corrupted when removed from its original contexts of production, dissemination or performance, but the position taken by many was that the "digital preservation of indigenous knowledge should not be seen as a means of replacing 
traditional forms of education in indigenous communities, but rather as something that will enhance or be used as an additional tool in this process" [20] (p. 27) (see other examples in $[8,9,23,24])$.

At PI/KHS, we too questioned whether an enhanced virtual environment could help rebuild connectivity between Inuinnait people, language, and land by highlighting —and even possibly recreating - the connections that daily life was struggling to sustain. From the start, we knew that any digital platform articulating the Inuinnaqtun ecosystem would have to be custom-built. Off-the-shelf databases and software are robust, but all too often have a predetermined structure for organizing and relating content. We needed a structure specific to Inuinnait. In 2006, PI/KHS partnered with the Geomatics and Cartographic Research Centre (GCRC) at Carleton University in Ottawa, Canada to develop its own solution to storing, organizing and preserving Inuinnait knowledge. GCRC was pioneering the concept of cybercartography, which sought to broaden the ways in which both spatial and non-spatial information could be visualized in digital environments. As defined D.R. Taylor Fraser, who coined the word, cybercartography entails "the organization, presentation, analysis and communication of spatially referenced information on a wide range of topics of interest and use to society in an interactive, dynamic, multimedia and multisensory format" [25] (p. 406). The interactive digital atlases produced by GCRC use a framework called Nunaliit, an open-source software package created to facilitate mapping input by community members with limited knowledge of geographic information processing [26]. The resulting platforms are capable of mapping connections and relationships between quantitative and qualitative information in a manner that can better mirror the sensory realities of various individuals and communities.

There were several qualities of the Nunaliit framework that immediately struck a chord with our organization:

(1) Nunaliit is open-source. All its code is publicly available and non-proprietary. Nobody owns it; nobody profits from it. This level of openness grants the possibility to push development into new, case-specific directions.

(2) Nunaliit is what is referred to as a distributed network, meaning that it connects multiple users through the same underlying database system. A benefit of this is that users can shape and visualize data according to their specific needs. Any new functions, features, or upgrades developed by one user, are then available to anyone else using the framework. The costs of maintaining the system over time are also distributed, making it more sustainable.

(3) Nunaliit is a relational database. In the simplest terms, this means that each piece of information entered into a Nunaliit database is a discrete document. A museum record of an Inuinnait parka, for example, would be its own document. A photo of that parka is a separate document. A photo of someone wearing the parka would be a separate document, a comment that someone makes about the person wearing the parka would be a separate document, and so on. This allows for a system in which data are not tied together in a conscripted way. They are a cloud of freefloating documents. These can be related to one another in different ways, forming ever-changing pathways of interconnection and association.

The ultimate benefit of the Nunaliit framework regarding our objectives of mapping both individual and collective cultural connections lies in its flexibility in terms of knowledge access. Nunaliit is capable of ingesting almost any form of digital media or information, and stores individual records in their own flexible documents that can, but are not required to, conform to an expected structure or schema. These schemas might organize documents with similar attributes such as map features, video interviews with elders, PDF scans of book pages, people, or photographs. This support for the flexible organization of data leaves users free to design and redesign as they go without being stuck with the original data design. This effectively results in large, non-linear webs of knowledge that can be organized, navigated, and presented in multiple ways according to specific needs and priorities. This unique design became particularly important in terms 
of the desire to create a database of Inuit knowledge that is actually amenable to Inuit structures of storing, teaching, and using the information it contains.

\section{Results}

Inuit traditions of mapping also informed our efforts to digitally chart an Inuinnaqtun ecosystem. The Inuinnaqtun term for maps is 'nunaujaq', which can be translated as being 'of the land'. No permanent maps have been recorded among pre-contact Inuit in the Canadian Arctic, although their presence has been theorized from a scattering of early three-dimensional relief maps carved from driftwood [16] (p. 6), and landscapes incised in ivory [27] (p. 47), [28]. The earliest Inuit maps were ephemeral in nature and took physical shape from the very landscape they sought to describe: charts etched in snow and sand, and intricate topographies assembled from sticks and stones ([14], [16] (p. 5)). These maps were not objective documents, in the sense of their orientation, scale, and representation of landscape being uniform and universally readable, but required an additional layer of communication and narration to complete the transfer of environmental knowledge. Material charts began to emerge only with the first encounters between Inuit and the western world. Close to 200 maps drawn by Inuit for explorers and ethnographers between 1818 and 1924 are known to exist, mainly from the contexts of non-Inuit expeditions requiring elaborate geographical information to navigate unknown surroundings. In line with ephemeral traditions of mapping, notes Renee Fossett [14] (p. 75), Inuit produced these graphic representations as "nothing more than incidental by-products of the oral teaching and learning process". Contrary to the standardized increments of miles employed in western-style maps, the units used by Inuit to estimate and represent distance resulted from the fusion of physical range and the (highly individualized) amount of time taken to travel that distance [16] (pp. 12-13). According to Peter Whitridge [28] (p. 226), this sophisticated form of cartographic representation-a hybridization of the ideal, real, natural and cultural-might even be seen as an improvement on western mapping, in which manipulation of scale: "represents a correction of the deficiencies of a two (or three) dimensional representation of a four-dimensional object (a journey)".

Like the traditional Inuit maps, our use of the Nunaliit framework to situate knowledge within an Inuinnaqtun ecosystem would have to be less about communicating a universal description of an environment than about allowing a series of highly personalized and hybridized stories to be retold. While the succession of digital tools we created over the next 15 years could never replace first-hand Inuinnaqtun experiences, they could serve as a way to document, organize and continue telling them, not as a single event, place name, or unique object, but as a larger atmospheric cloud of conversation and association that more closely mirrored the workings of an ecosystem. In detailing our resulting efforts, this article will specifically focus on describing the role of cultural compatibility in our design of digital platforms, with more detailed explanations of their methodology and functionality already available through other publications about the projects $[29,30]$.

\subsection{The Kitikmeot Place Name Atlas: Mapping Inuinnaqtun Connections to Land}

In 2006, the development of PI/KHS' first digital platform, called the Kitikmeot Place Name Atlas, began [31]. As its name suggests, this mapping tool was created to inventory and communicate Inuinnaqtun toponyms. Since 2000, PI/KHS researchers meticulously documented toponyms through community-engaged programming, elders' meetings and field research, with the goal of reviving their usage through increased local awareness and official recognition on territorial and national topographic maps. We looked to Nunaliit's framework to further support and visualize the relationships and language underlying this sense of place.

The Place Name Atlas was designed as scrollable digital map of the Inuinnait region with all named places geolocated (see Figure 3). In collecting toponyms for the dataset during land and map-based interviews with elders, close attention was paid to recording knowledge peripheral to the actual names-a methodology adapted from 
Ludger Muller-Wille's place name surveys in Nunavik [32]. As more thoroughly detailed in a 2014 publication [29], this included the recording of multiple components for each landscape feature:

1. The location and extent of geographical features covered by each place name.

2. The Innuinaqtun geographical entity or entities represented by the place name.

3. The pronunciation of each place name.

4. The proper representation of each place name in the orthographies used by speakers of the Inuinnaqtun dialects who use the place name.

5. The meaning of each place name.

6. The oral traditions associated with the name, including stories, legends, and songs.

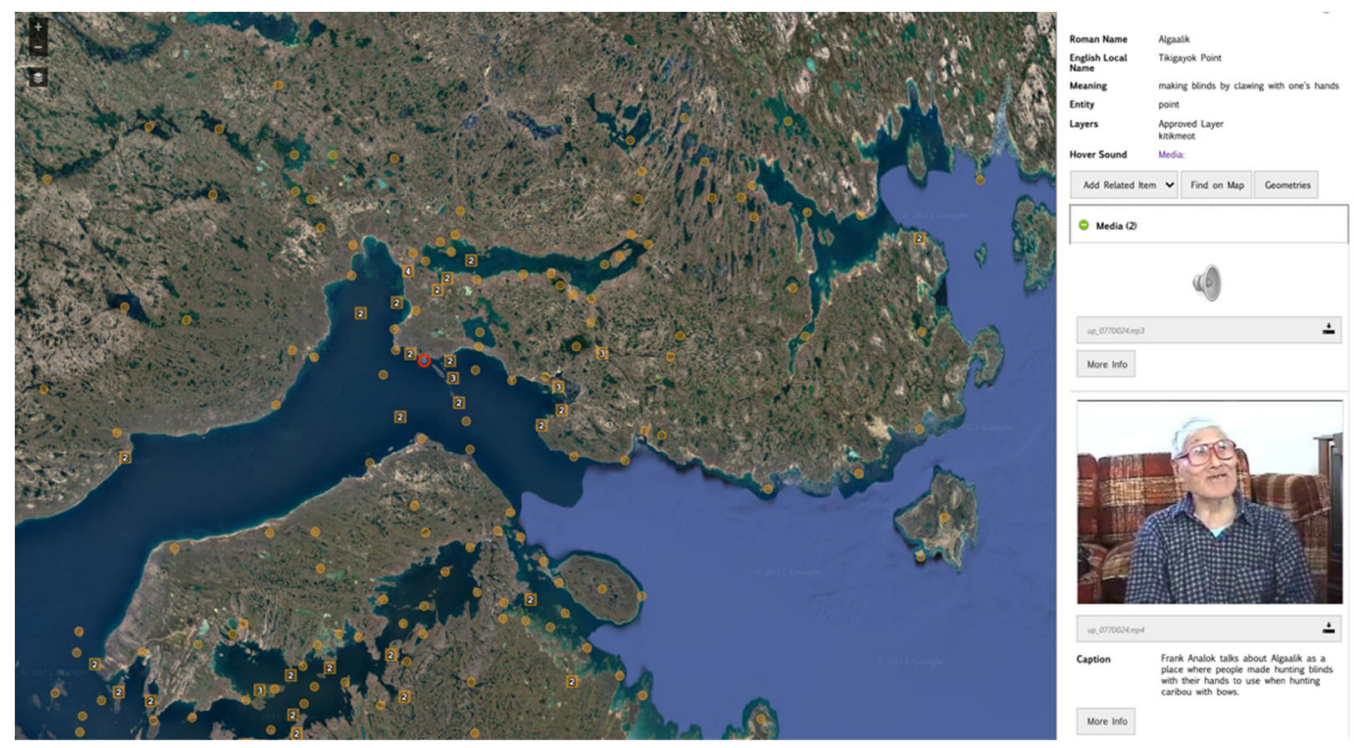

Figure 3. A video of elder Frank Analok is linked to the Tikiraaryuk site and describes its history of use for seal hunting and iglu building. Each yellow dot on the map represents a unique place name and associated data.

More than 1300 places were recorded using this methodology and incorporated into the Atlas.

Language plays an important role in this platform. The use of spoken Inuinnaqtun was prioritized to help preserve the integrity of the primarily oral language and its pronunciations. Inuinnaqtun orthography is still largely unstandardized, with different generations accustomed to different variations in spelling. Reliance on spoken versions of place names by language experts ensures that authoritative versions are in place. Audio files of each name being spoken by a language expert were embedded in each mapped place, and are activated when hovered over or selected.

The platform was also designed to integrate human relationships into its mapping of place names. As previously mentioned in this article, landscape knowledge is traditionally transferred through mentorship by elder members of a community, who instruct younger individuals in the physical navigation of sites, the activities that take place there, and the body of oral tradition that surrounds the place. While this form of interactive, 'on-site' education is not possible in a virtual environment, we focused on introducing additional interview and media content from local elders and land users into named places. Interviews and video recordings of individuals engaging with the landscape, or narrating the mythology and history of specific sites, were made accessible for many locations, lending a much-needed human element to its interpretation (see Figure 3).

Through mapped place names, integrating interviews and spoken translations, the Kitikmeot Place Name Atlas was able to digitally bridge the Inuinnaqtun language, people and place. A distinct challenge for the Atlas was negotiating the element of physical 
experience that is so critical to Inuit traditions of learning about the land. While virtually engaging with a landscape can relay many educational details, it is very different from being physically present on the land. PI/KHS navigates this gap using parallel non-digital programs such as land-based cultural camps, hunting, and harvesting excursions. We continue to look for ways in which the experience of being 'on the land' can be incorporated into our digital site. One attempt to heighten the virtual experience of named places was to introduce photospheres of individual sites that allow users to visually pan around the environment being described (see Figure 4). As other Arctic digital heritage projects have demonstrated [33,34], the use of panospheres and 3D modeling have strong potential to connect people to remote environments that they cannot otherwise visit in person.

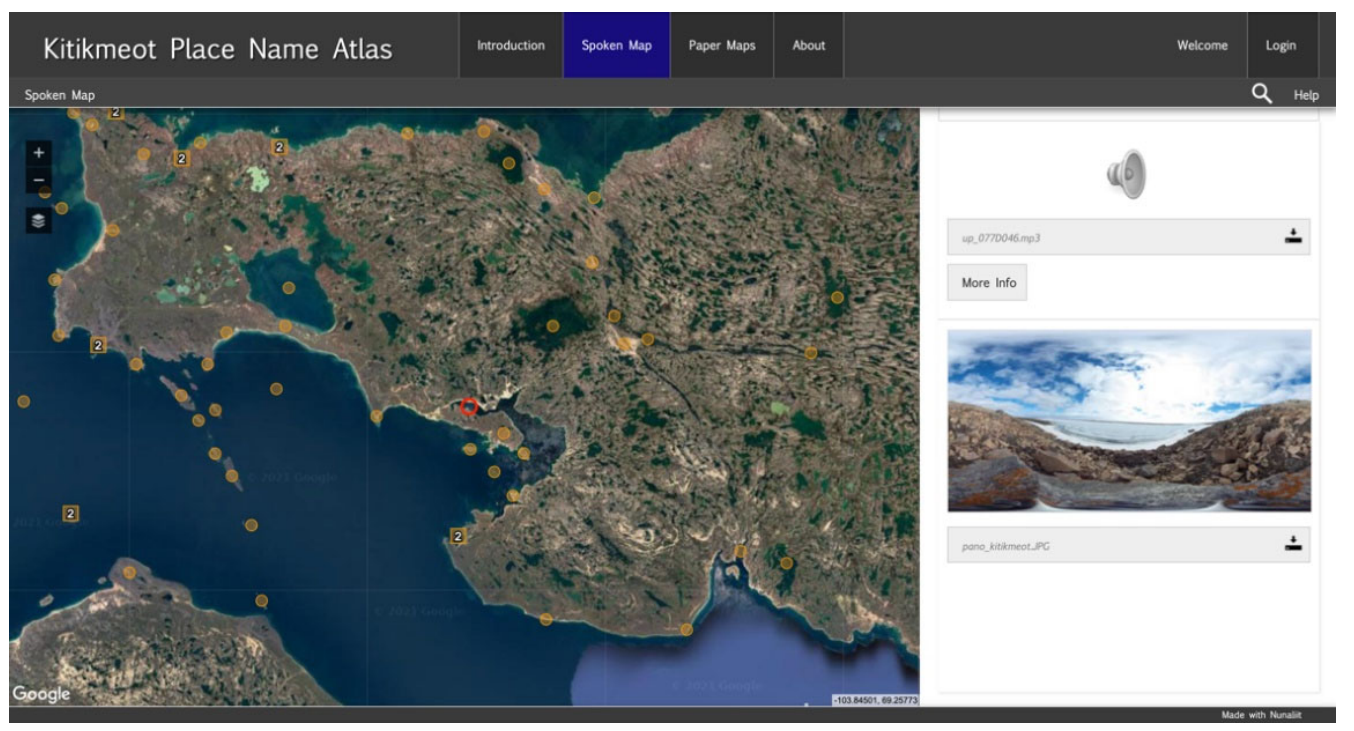

Figure 4. A photosphere of the Kangiqhuk area allows individuals to see the areas being described. This functionality was designed to facilitate visual engagement with remote sites that few people can travel to.

\subsection{The Fifth Thule Expedition Atlas: Mapping Inuinnaqtun Connections to the Past}

While the Kitikmeot Place Names Atlas spoke to Inuinnait connections with natural landscape, we also wanted to accentuate the historical topography of the Inuinnait region. For many Inuinnait, the physical landscape is deeply layered in experience and narrative. The act of travelling through, and engaging with, this storied landscape is an important way for Inuinnait to re-affirm their contemporary connections to the land and the ancestors who once lived there. As Béatrice Collignon notes [1] (p. 90), the land occupied by Inunnait cannot be expressed through a simple map, "with nothing more than axes of travel, points that mark camps and hunting areas. Through human experience and storytelling, the landscape becomes a memoryscape, a humanized environment. The territory becomes a world filled not merely with its living people (who are not numerous), but also of their ancestors, their adventures and misadventures, their bones and their spirits".

In line with the goal of digitally representing an Inuinnaqtun landscape, we were interested in re-establishing connections between current Inuinnait populations and the rich ecosystem of knowledge, beliefs and relationships that informed Inuinnait culture in the past. The focus of this work was ultimately found in the Fifth Thule Expedition. Between 1921 and 1924, Danish-Greenlandic ethnographer Knud Rasmussen led a research team across the whole of the North American Arctic-from Greenland to Siberia-acquiring detailed observations, collections and documentation about the Inuit cultures they encountered (see, e.g., [7,35-38]). The linguistic and cultural fluency of Knud Rasmussen-who was of mixed European and Greenlandic Inuit heritage-allowed him to speak with Inuit in their own tongue and compile detailed information about their cultural and social 
environments. Rasmussen spent a total of three months specifically working among the Inuinnait [39,40].

In anticipation of the centennial anniversary for this important expedition, PI/KHS wanted to ensure that the rich cultural ecosystem it documented was both defined and made available to contemporary Inuinnait communities [30]. In 2014, the organization partnered with the National Museum of Denmark - the recipient of many of Rasmussen's collectionson a project to bring Inuinnait elders and staff to Denmark to reunite them with material collections, photographs and textual recordings from the expedition so as to interpret the ongoing importance of historical materials to the culture [41]. The methodology for this research was not dissimilar to that of collecting placenames. Elders visiting the collections provided rich cultural information, including Inuinnaqtun terminology for the items and their composite parts. They also told stories about their personal experience with the objects, and often talked about seeing them used in their childhood by their parents and grandparents. All proceedings were video-recorded. These interviews were part of our larger endeavour to isolate and extract Inuinnait knowledge-in the form of oral traditions, songs, traditional place names, linguistic information, genealogical information, Inuitdrawn maps, photographs, and ethnographic objects-from the non-Inuit narrative and theories that originally guided the expedition.

Working alongside GCRC's developers, we used the Nunaliit framework as a foundation to map the intricate worldview of Inuinnait, as held both at the time of Rasmussen's visit 100 years ago, and in the present day. The platform was called the Fifth Thule Expedition Atlas [42], and was developed with four key functions in mind:

1. Providing digital access to Inuit knowledge gathered on the expedition;

2. Providing opportunities for Inuit to verify and enhance he tknowledge collected by the expedition;

3. Linking the results of contemporary research and Inuit experiences to expedition findings;

4. Creating opportunities for Nunavummiut to interact with the expedition objects and environments in augmented reality environments.

As a first approach to situating Inuinnait knowledge in a digital environment, our project gravitated back to using a spatial, map-based interface similar to the Place Name Atlas (see Figure 5).

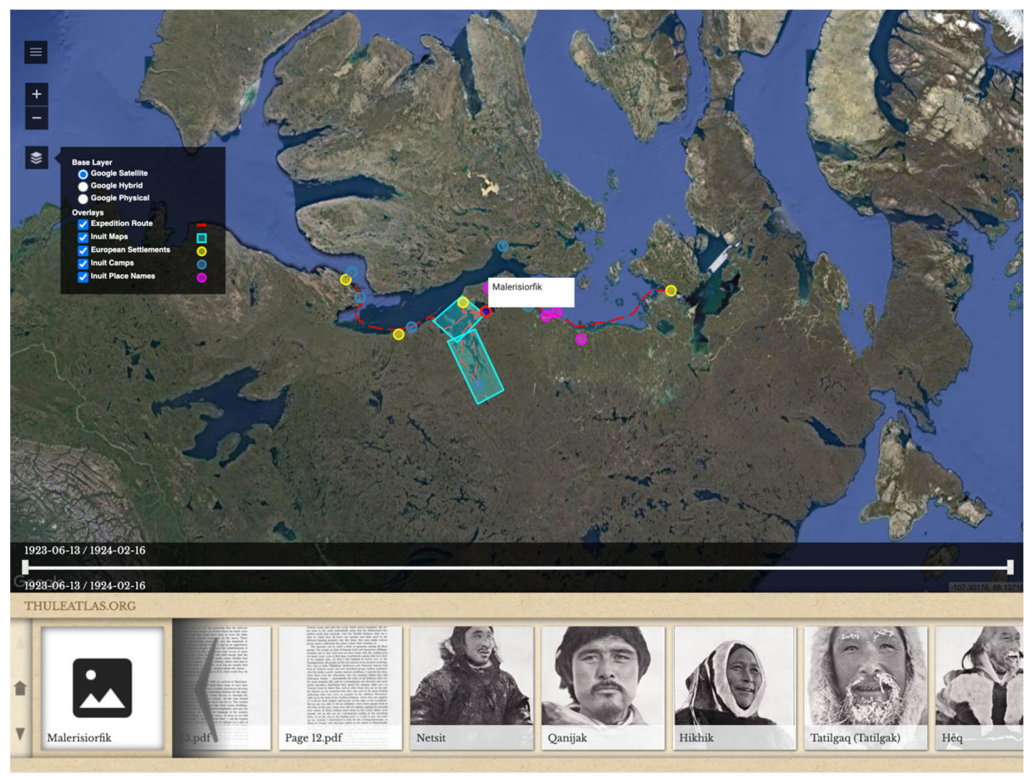

Figure 5. A geospatial map of the Fifth Thule Expedition's course through the Inuinnait region. Clicking on a specific location summons the people, knowledge and collections sourced from that location. 
This interface allows users to cartographically access information through an area map that visualizes locations such as the expedition routes, culturally significant places, and Inuit camps encountered by the expedition. Clicking on locations in the map will summon cultural documentation related to that place, whether these are photos of Inuit who once occupied the area, records of the knowledge they imparted, or transcribed songs and stories. This reliance on a more conventional cartographic methodology facilitates its use by Inuit elders and land users [43], and increases the potential to link the knowledge to additional geographic applications such as the Place Names Atlas.

The challenge of representing Rasmussen's rich glimpse into the interconnected lives of Inuinnait, language and land required us to do more than physically plot the information on a map. A second interface for the Fifth Thule Atlas was created to provide direct access to interactive and searchable PDF versions of Rasmussen and his colleagues' expedition reports. All Inuit knowledge featured throughout the text-whether in the form of songs, photos, place or person names, etc.-was isolated as discrete documents, which could be selected and explored in greater detail. These documents could be manually connected to other pieces of contextual information-a kayak gathered by the expedition, for example, linked with both the museum records and an elder interview about the same kayak recorded during our Denmark travels 100 years later-forming long chains of associated information that provide a fuller understanding of how the information is associated with Inuinnait lives. Every knowledge document entered into the Atlas is also accompanied by a community-driven report that allows users to add information, edit content, or contribute additional metadata (see Figure 6).

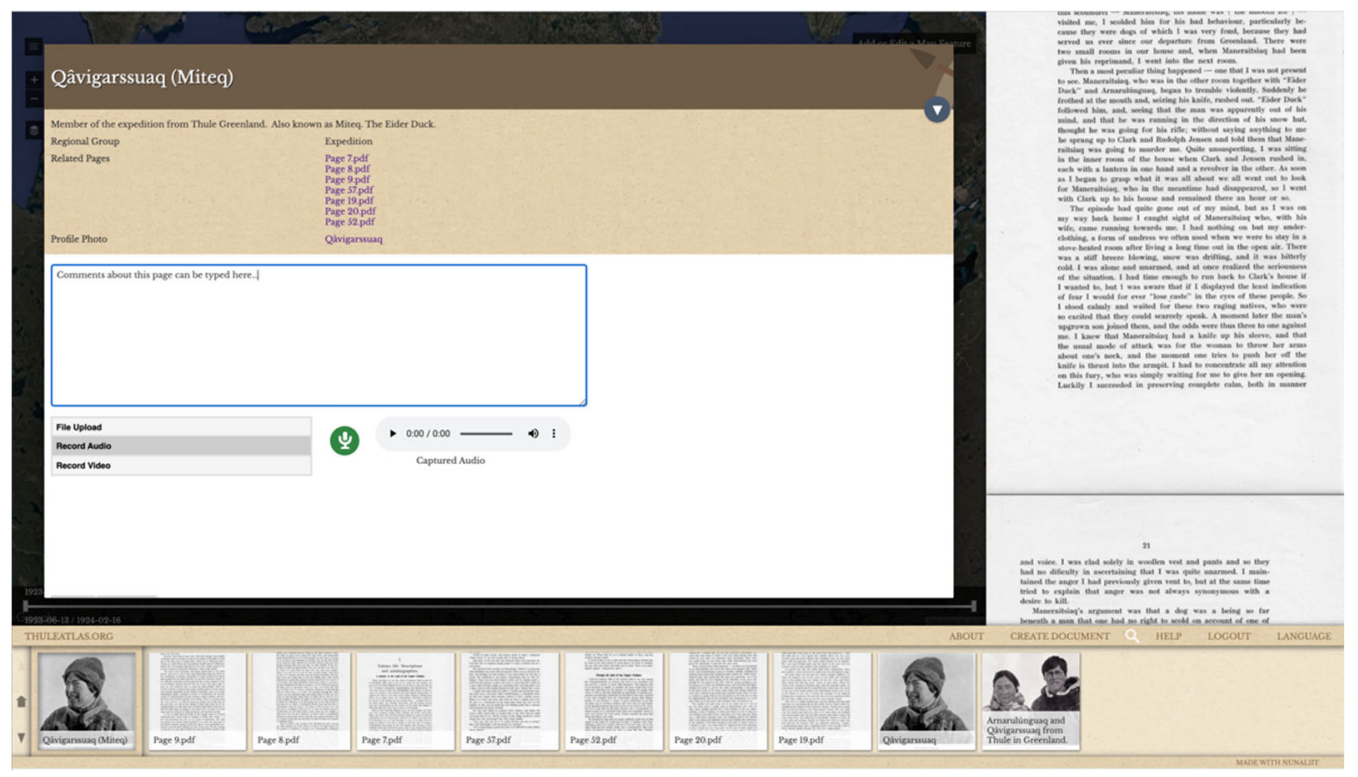

Figure 6. Functionality allows for users to link their own text, audio and video commentaries to specific expedition report pages or extracted Inuit knowledge documents.

The format of these contributions encompasses written text, audio and video recordings through the computer browser, or as additional files uploaded directly by a user. This parallel version of the Fifth Thule reports helps Inuinnait voice their own connections to this historical content and enhance/qualify its meaning in a more contemporary context. To date, this application has been used for purposes as diverse as community video uploads detailing the making and use of tools reconstructed from details and images in the expedition reports, to versions of Inuinnaqtun songs translated from the reports into contemporary Inuinnaqtun orthography [44].

The Atlas' third form of interface allows users to engage directly with subject categories of interest such as place names, people, oral traditions, photographs, maps, routes, and report pages. This interface exists as a series of visual 'tiles', which can be navigated 
according to the user's specific interests. As exemplified in Figure 7, a user interested in people encountered by the expedition can select the 'people' tile from the list of categories, and the tile row will re-populate to show all the individuals encountered on the expedition. When the desired person is selected, the tiles further re-populate with all documented information related to that particular person, including the place in which they were encountered, tools they made, and songs, stories and maps that they created.

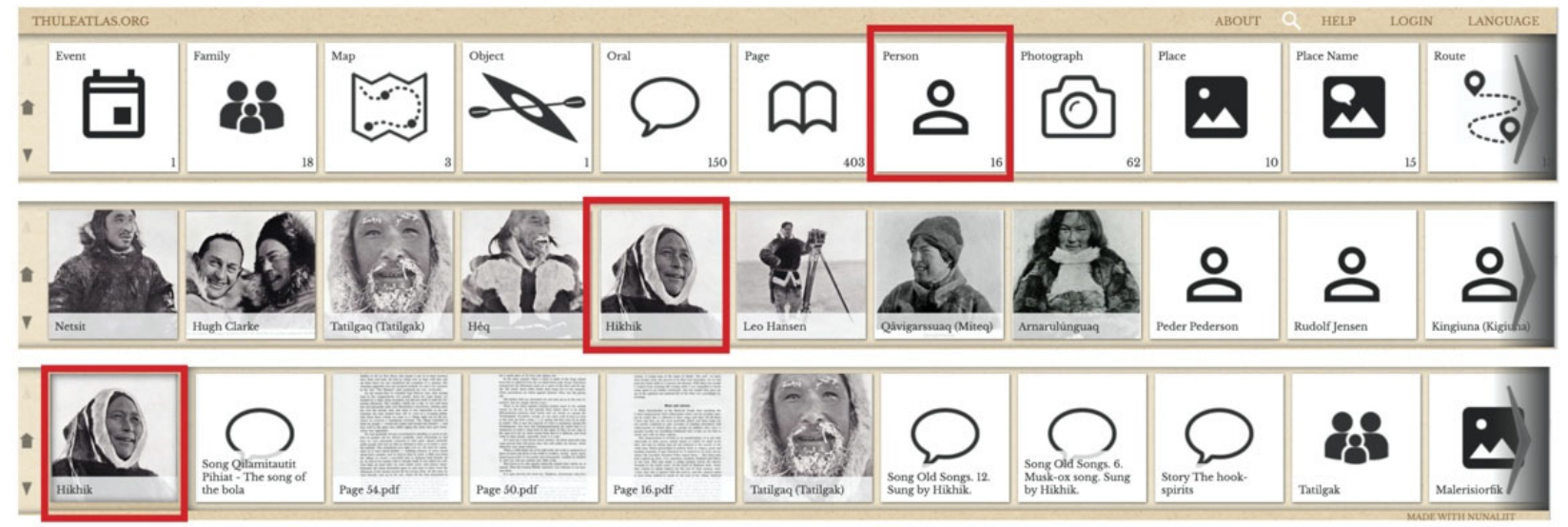

Figure 7. This sequence of three tile selections illustrates how users can navigate various categories of knowledge according to their specific interests, and how each choice of tile will cause the row to repopulate with all documents related to the selection.

The Fifth Thule Atlas facilitates Inuinnait connections with historical knowledge by providing various access points to the information. It allows users to navigate documents in a spatialized manner for the easy location of relevant information. Most Inuinnait are aware of the areas occupied by their families prior to settlement and can locate them along the mapped expedition route to delve deeper into the knowledge these ancestors. It also encourages users to more critically navigate Inuinnait knowledge, as contained in expedition reports, gauging for themselves how the information may have been influenced by the motivations, agendas, and anthropological theories of the researchers that collected them. The functionality of commenting allows Inuinnait to begin redressing perceived distortions of cultural information by added to existing records, further shaping the ways in which they are accessed and navigated. This dialogue between the past and present ensures that the Inuinnaqtun knowledge being represented is not static or fixed, but an ever-changing landscape of association, learning and transfer.

\subsection{The Inuinnait Knowledge Bank: Mapping Inuinnaqtun Connections in a Local and Global Context}

A critical part of mapping the connections between contemporary populations and a broader Inuinnaqtun ecosystem is ensuring that the Inuit knowledge detailing those connections is accessible to as many Inuinnait as possible. As generations of Inuinnait grow more distant from traditional lifeways, there is an increasing reliance on secondary sources for the recovery of cultural knowledge that eludes collective memory, and even the Arctic itself, through storage in museums, archives and memory institutions around the world. As demonstrated by the Fifth Thule Expedition, this includes images, material collections, and information sourced directly from Inuinnait and recorded in the relative permanence of fieldnotes and photographs. Based on the success of the Fifth Thule Atlas, we began to more deeply consider how the recovered collections can strengthen an Inuinnait ecosystem.

In 2019, we began re-developing the Nunaliit framework to fashion a customized collections management system to broaden engagement between Inuinnait and the dispersed records of their cultural knowledge. Called the Inuinnait Knowledge Bank [45], this platform was designed to compile records from a vast number of museums and archives- 
including PI/KHS' own digitized archives and donated private collections- with the ultimate goal of a centralized and searchable record existing for every digitally available Inuinnait object, photo and archives document around the world. The consolidation of geographically distributed knowledge and collections into a single digital portal that can be managed by Inuit supports local control of that knowledge and increases the possibilities to apply it according to Inuinnaqtun priorities. While still a work in progress, the Inuinnait Knowledge Bank is currently populated with roughly 3000 records and continues to grow in interesting new directions (see Figure 8).

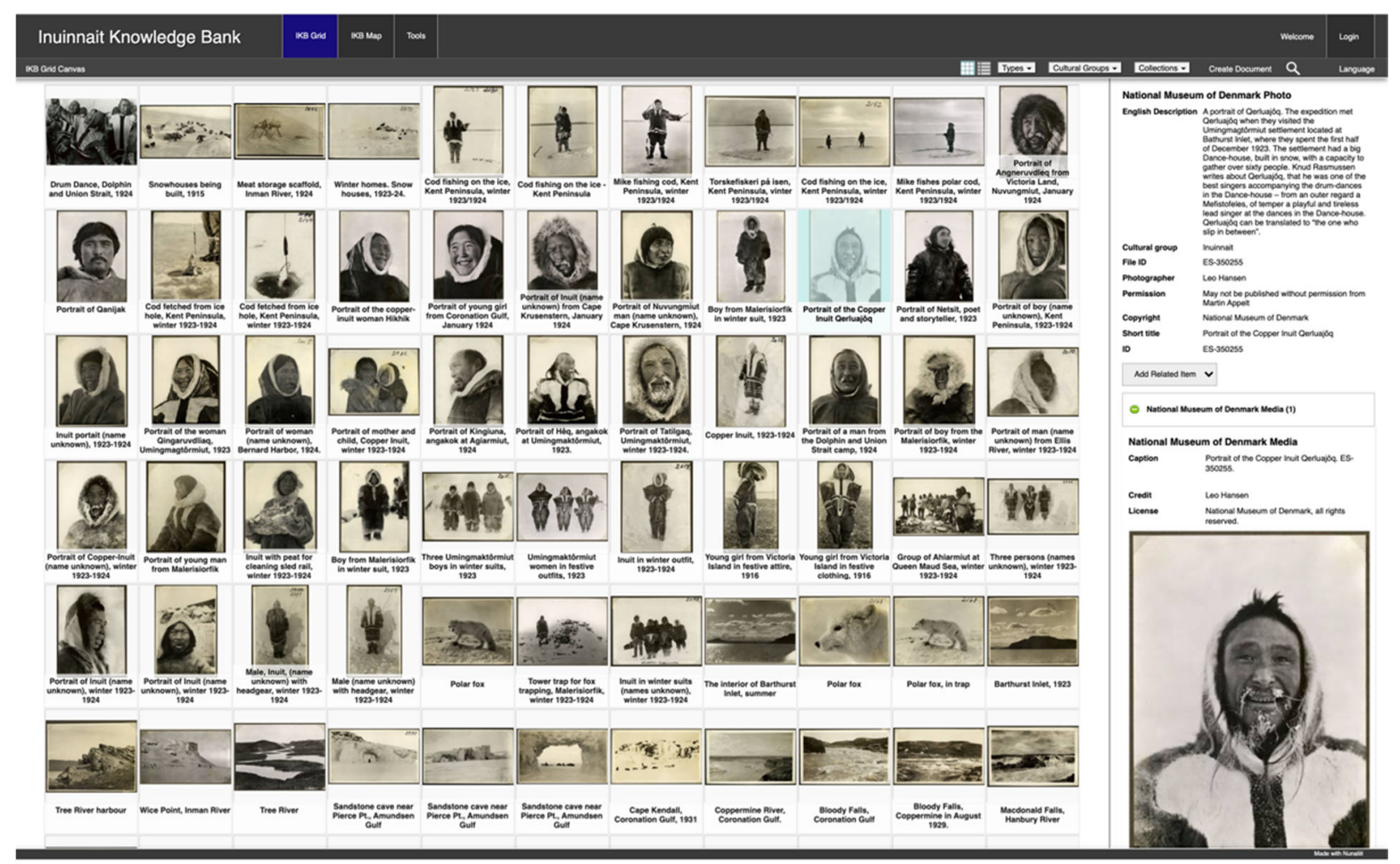

Figure 8. An overview of the records contained in the Inuinnait Knowledge Bank's collection management system. Institutional metadata for each record are displayed verbatim on the right-hand side of the screen.

The Knowledge Bank seeks to restore traditional pathways and priorities for collective knowledge management, leveraging the expertise of community members by providing them with three essential ingredients for knowledge-sharing: a way to access geographically dispersed records; a repository to store and manage local knowledge; and a digital framework to support traditional networks and relationships for knowledge sharing and transmission. These functions will be explored in turn.

Traditional content management systems follow a similar approach to western mapping in that each record is granted a fixed position in an overall collection. These records are defined through key attributes, and take their place alongside similar item categories, time periods or creations by specific artists or makers. In drawing together a vast number of different institutions' collections-each with their own key attributes-the Knowledge Bank seeks a more a emic cultural approach to organization and display. To begin, each record in the Inuinnait Knowledge Bank is populated with its holding institution's original language and metadata to ensure that the integrity of its existing documentation is maintained (see Figure 8). To build on this record, we applied the Fifth Thule Atlas' functionality for user-submitted text, audio and video comments, allowing the records to be further layered with Inuinnaqtun terminology and cultural content to broaden their context. This might entail uploading Inuinnaqtun language descriptions, metadata attributes deemed to 
be missing from the original record, or entirely novel material that a user feels should be referenced alongside the document or object (see Figure 9).

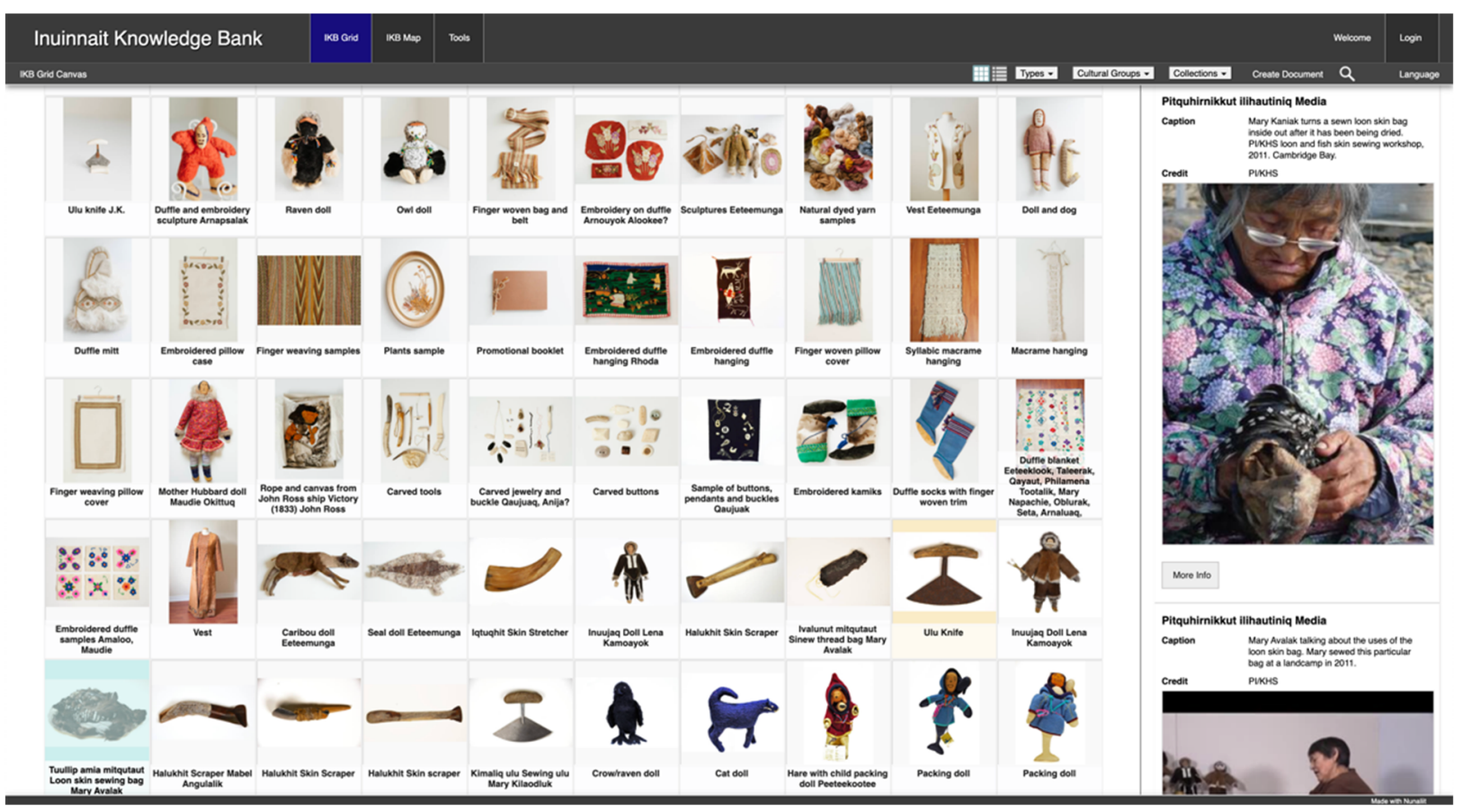

Figure 9. Community submitted records about a loon skin bag help to better position collections within a cultural context. The multiple videos seen to the right of the screen demonstrate a loon bag's manufacture techniques, Inuinnaqtun terminology, and a host of related information regarding everything from harvesting techniques for loons to cultural prescriptions for materials that should be carried within such a bag.

We are currently implementing improvements such as content tagging to allow an even broader audience to describe, categorize and highlight specific records, and share new language and information with one another. With this functionality, users can create and apply existing and unique categories to organize and search the content, highlight various relationships between individual digital records, and easily identify which collections/records are priorities for research or programming through sentiment tagging (i.e., liking). Through tagging, we hope to eventually implement a unique Inuit content licensing system, in which users can layer objects with descriptions of cultural protocols to engage with the collections in both digital and physical form.

It is our hope that the Inuinnait Knowledge Bank is adopted by northern communities as a central tool to access and contribute to the knowledge about Inuinnait lifeways both past and present. Despite this being a virtual and, in many ways, global endeavour through its reliance on the Internet and foreign collections, we have tried to ensure that the knowledge continues to reside in the Inuinnait region. The Inuinnait Knowledge Bank is currently housed in a dedicated server at the May Hakongak Cultural Centre in Cambridge Bay, as an early priority for our digital work was the ability to identify a specific location when asked by community members where the accumulated knowledge is being stored. Controlling the physical location of digital knowledge comes with additional benefits. A server linked to a wifi network can give local people faster and easier access to its contents. It also serves as a gateway for knowledge, allowing community members to decide whether information should remain exclusively within their community, be shared with neighbouring Inuinnait communities, or be available to everyone using the Internet. This tiered approach is key to fostering the development of local data ownership and sovereignty. 


\section{Discussion}

Over the last 15 years, our Inuinnaqtun mapping program has introduced a novel language for information-sharing and storytelling among Inuinnait. This language draws from the age-old contexts of Inuit culture, but also lies squarely in newness and the digital realm. A major question underlying this work is whether or not this form of hybrid platform serves as an effective form of communication, in the sense that it can connect a once thriving cultural ecosystem with new generations of Inuit without first-hand experience of its full richness, sophistication and fluency. This question recalls the same conundrum of digital adaptation vs. assimilation brought up earlier in this paper.

The major strength of our digital mapping platforms lies in their ability to document and preserve the stories and cultural knowledge held by Inuinnait elders. The perspectives of individuals who spent their formative years on the land-immersed in the fluency of the Inuinnaqtun language and ecosystem - are both an increasingly limited resource and essential for carrying forward the intricate network of connections that once threaded the Inuinnait world into a coherent whole. These contemporary voices are further magnified through the addition of temporally deeper and geographically dispersed records, in the form of historical recordings, place names, photos, and material collections. Our platforms serve to define these remembrances and fragments of information, anchoring them in space and time so that the richness and depth of the Inuinnait presence in their region can be visualized and, in many cases, directly heard. When considered as maps, they illustrate the coverage of Inuinnait knowledge: a topography of convergences between people, land, and language.

A return to Inuinnait conventions of mapping, however, highlights the need for a very different form of cartography. Traditionally, Inuit maps were guided by first-hand experience, encounter, and the stories that these create. They detailed a personal journey from the vantage of that individual. It is a very different feeling to be physically present in an Arctic landscape than to engage with it on a screen; the same is true for the handling of material objects and collections [46]. As much of the world has discovered during COVID-19 and the shift to virtual meetings, a similar rule applies to our relationships with other people. Something is always lost with remove. To re-quote Renee Fossett on the performative nature of Inuit maps [14] (p. 75), is it possible to also think about the platforms we have produced as "nothing more than incidental by-products of the oral teaching and learning process"? If so, what does this process entail?

This final section of our paper briefly considers the activities surrounding the creation and usage of our mapping platforms by Inuinnait as the key ingredient for their proposed purpose of knowledge transfer and mending the Inuinnaqtun ecosystem. We will begin with the land. As discussed, landscape knowledge is traditionally passed on through mentorship by the elder members of a society through activities and the recounting of oral tradition. The mentee accordingly builds their own landscape ontology by integrating this knowledge while practicing/gaining their own experience in that environment. For a digital platform to accurately reflect this relationship, the encounters it provides with the land must be as real as possible. While we have used photospheres to augment landscape visualization, they do little to capture the full sensory and physical immersion that would traditionally accompany learning in, and from, a place. The critical element of communicating connectivity between places is also missing - of understanding an area not as an individual location, but as one part of larger network of places. To better align our platforms with these cultural understandings of place, we ultimately need to move them offline. We continue to look at the ways in which land knowledge within the Atlases could be integrated with GPS and inReach technologies as a way for users to access and contribute to digital content about locations while being physically present.

Fluency of language is a similar issue. Like land, language does not exist as a series of isolated points or words. It is dynamic, highly fluid and context-specific. Our platforms have targeted the accuracy of language through spoken-word functionality, and the ability of users to build upon historical fieldnotes, collection records and institutional metadata 
with Inuinnaqtun equivalents. We have introduced videos and audio transcripts created in the Inuinnaqtun language as supporting documentation for digital records. However, in order to thrive, the Inuinnaqtun language needs to transcend the screen and enter daily use and application. This has become our new focus for the platform. In 2018, PI/KHS began a pilot program in conjunction with its Fifth Thule Expedition Atlas to translate the Inuinnaqtun recorded in Knud Rasmussen's 'Intellectual Culture of the Copper Eskimos' [7] into a more accessible script. Ramussen employed a personalized orthography based on Western Greenlandic, which made the Inuinnaqtun terms he recorded all but unreadable to Inuinnait. A team of language experts across the Inuinnait communities was organized to begin extracting and translating Rasmussen's script, transcribing Inuinnaqtun songs and stories [44], and create terminology for entry into a separate Nunaliit-based platform designed as virtual Inuinnaqtun lexicon [47]. The importance of this translation work for the Inuinnaqtun ecosystem lies in the fact that it put language back into circulation; old songs were re-sung during drum dances, past stories were made new through their retelling, and terminology was mined for technical nuance to enhance the accuracy and scope of current conversations. This provides a strong example of how our mapping platforms can serve as a resource to connect speakers and resituate language in the real world rather than in digital space.

Last, but not least, we would like to consider if and how our platforms contribute to the strengthening of Inuinnaqtun relationships. In a fully functional Inuinnaqtun ecosystem, cultural skills and language are acquired through observation, listening and general proximity to experts: a highly social process of knowledge transfer. With the breakdown of intergenerational knowledge relationships and oral transmission, social interactions of this nature are harder to maintain. The mapping platforms we have developed excel in facilitating connections with individuals from the past. Through the Fifth Thule Atlas, users can gain access to stories, worldview and collections gathered from their ancestors 100 years ago. Video content enhancing the digital records in the Kitikmeot Place Names Atlas and Inuinnait Knowledge Bank also provide an element of social sharing and storytelling featuring more contemporary populations. Despite this, the interactive element of direct person-to-person engagement is still missing from the platform. Until this functionality develops, we capitalize on the mapping platforms as a common focus to bridge the interests and skillsets of different generations. This primarily occurs through data entry workshops partnering tech-saavy youth with local elders, a strengths-based approach which allows all participants to share and learn (see Figure 10).

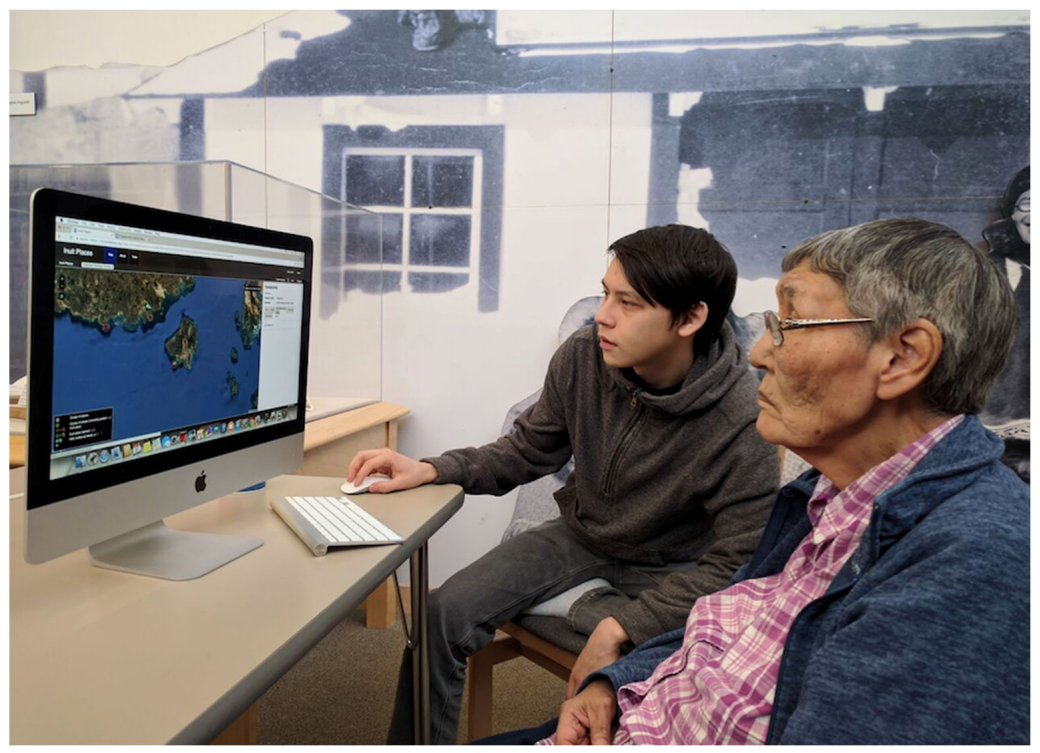

Figure 10. A Cambridge Bay student is partnered with Mabel Etegik to assist with navigation and content entry in the Kitikmeot Place Names Atlas. 


\section{Conclusions}

In seeking out new approaches for mapping and reconnecting the Inuinnaqtun ecosystem, it is important to recognize that our ambitions do not lie in revolutionizing the ways that Inunnait tell their stories, engage with one another, or learn from the land. These practices have been honed for centuries and have no room for improvement. The ultimate aim of this work is to widen the pool of content for future listeners and learners; to broaden the perspective of new generations with the stories of the old. While real-world experience and engagement remain the best ways for Inuinnait to understand and repair the intricate connections of their culture's ecosystem, should these mechanisms fail due to the widening gaps between generations, the pressures accompanying urban settlement, and the balance of local and global identities, we believe that a carefully designed cartographic application can provide both a beneficial repository for Inuinnait knowledge and the common focus required to renew its circulation in daily life.

Author Contributions: Conceptualization, Brendan Griebel and Darren Keith; methodology, Brendan Griebel and Darren Keith; project administration, Brendan Griebel, Darren Keith; funding acquisition, Brendan Griebel, Darren Keith; writing - original draft preparation, Brendan Griebel; writing-review and editing, Brendan Griebel, Darren Keith. All authors have read and agreed to the published version of the manuscript.

Funding: The development of our digital mapping program took place over the course of 15 years, and, during that time, received support through various grants from the Government of Nunavut, the Canadian Internet Registration Authority (CIRA), Canadian Heritage, Canada Council for the Arts, and Polar Knowledge. We are thankful to all those who have invested in the success of this program.

Institutional Review Board Statement: Not applicable.

Informed Consent Statement: Informed consent was obtained from all individuals who contributed Inuit knowledge to our digital platforms through interviews, photographs or other forms of media.

Data Availability Statement: Not applicable.

Acknowledgments: The Inuinnaqtun mapping project has only been possible through the contributions of Inuinnait, who have shared their language and deep knowledge of their culture and language to realize its creation. We would particularly like to thank PI/KHS' staff, Elders-in-Residence and Board members, who have dedicated their time and passion to recording their knowledge for future generations. Of particular note are Kim Crockatt, Pamela Gross, and Elayne Merritt (project leadership and administration), Emily Angulalik and Gwen Angulalik (translation and interpretation), Lyndsey Friesen (project communications), and elders from our research team including Mary Avalak, Mabel Etegik, Mary Kilaodluk, Mary Kudlak, Jimmy Oghina, Margaret Oghina, Annie Atighioyak, Mary Kaniak, Bessie Omilgoetok, Frank Analok, Joseph Tikhak, Lena Kamoayok, and many more. We would also like to acknowledge the support and digital collection contributions we have received from museums around the world, with the Arctic departments at the National Museum of Denmark, the Smithsonian Arctic Centre, Canadian Museum of History, and Arctic Institute of North America being of particular note for their generosity and time. Last, but not least, we wish to thank the dedicated staff of Carleton University's Geomatics and Cartographic Research Centre including Fraser Taylor, Amos Hayes, J.P. Ficet, Peter Pulsifer, and Rob Oikle for their ongoing efforts in helping us develop their Nunaliit framework into our vision for Inuinnaqtun mapping tools.

Conflicts of Interest: The authors declare no conflict of interest that may have influenced the representation or interpretation of reported research results. Funders had no role in the design of the study; in the collection, analyses, or interpretation of data; in the writing of the manuscript, or in the decision to publish the results.

\section{References}

1. Collignon, B. Knowing Places: The Inuinnait, Landscape and the Environment; Circumpolar Research Series No.10; CCI Press: Edmonton, AB, Canada, 2006.

2. Bennett, J.; Rowley, S. Uqalurait: An Oral History of Nunavut; McGill-Queen's University Press: Montreal, QC, Canada, 2004.

3. Hickey, C. An examination of processes of cultural change among nineteenth century Copper Inuit. Etud. Inuit Stud. 1984, 8, 13-35. 
4. $\quad$ Stefansson, V. My Life with the Eskimo; Macmillan: New York, NY, USA, 1913.

5. Jenness, D. The Life of the Copper Eskimos; Report of the Canadian Arctic Expedition, 1913-1918 (Southern Party), 2(A); King's Printer: Ottawa, ON, Canada, 1921.

6. Jenness, D. The Cultural Transformation of the Copper Eskimo. Geogr. Rev. 1921, 11, 541-550. [CrossRef]

7. Rasmussen, K. Intellectual Culture of the Copper Eskimos; Gyldendal: Copenhagen, Denmark, 1932.

8. Nunavut Implementation Commission (NIC). Footprints in New Snow; NIC: Iqaluit, NU, Canada, 1995.

9. Christensen, N.B. Inuit in Cyberspace: Embedding Offline Identities Online; Museum Tusculanum Press: Copenhagen, Denmark, 2003.

10. Pennicault, N. Inuit, Les Internautes du Haut du Monde, Libération. 1996. Available online: www.liberation.com (accessed on 28 April 2021).

11. Savard, J.A. Theoretical debate on the social and political implications of Internet implementation for the Inuit of Nunavut. Wicazosa Rev. 1998, 13, 83-97. [CrossRef]

12. Dunn, L.; Gross, P. Food-Sharing Practices Online in the Facebook Group Cambridge Bay News. Étud. Inuit Stud. 2016, 40, 225-243. [CrossRef]

13. McGrath, J. The Qaggiq Model: Toward A Theory of Inuktut Knowledge Renewal; Nunavut Arctic College Media: Iqaluit, NU, Canada, 2019.

14. Fossett, R. Mapping Inuktitut: Inuit views of the real world. In Reading beyond Words: Contexts for Native History; Brown, J., Vibert, E., Eds.; Broadview Press: Peterborough, ON, Canada, 1996; pp. 74-94.

15. Spink, J.; Moodie, D. Eskimo Maps from the Canadian Eastern Arctic; Cartographica Monograph, 5, 1972; University of Toronto Press: Toronto, ON, Canada, 1972.

16. Heyes, S.; Jacobs, P. Losing Place: Diminishing Traditional Knowledge of the Arctic Coastal Landscape. In Making Sense of Place: Exploring Concepts and Expressions of Place through Different Senses and Lenses; Vanclay, F., Malpas, J., Higgins, M., Blackshaw, A., Eds.; National Museum of Australia: Canberra, Australia, 2008; pp. 135-154.

17. Damas, D. Arctic Migrants/Arctic Villagers: The Transformation of Inuit Settlement in the Central Arctic; McGill-Queen's Press-MQUP: Kingston, ON, Canada, 2002.

18. Chikonzo, A. The potential of information and communication technologies in collecting, preserving and disseminating indigenous knowledge in Africa. Int. Inf. Libr. Rev. 2006, 38, 132-138. [CrossRef]

19. Christie, M.J. Computer databases and Aboriginal knowledge. Learn. Commun. Int. J. Learn. Soc. Contexts 2004, 1, 4-12.

20. Hunter, J. The Role of Information Technologies in Indigenous Knowledge Management. Aust. Acad. Res. Libr. 2005, 36, 109-124. [CrossRef]

21. Stevens, A. A different way of knowing: Tools and strategies for managing indigenous knowledge. LIBRI 2008, 58, 25-33. [CrossRef]

22. Sullivan, R. Indigenous Cultural and Intellectual Property Rights: A Digital Library Context. D-Lib Mag. 2002, 8, 5. Available online: http:/ /www.dlib.org/dlib/may02/sullivan/05sullivan.html (accessed on 10 March 2021). [CrossRef]

23. Alexander, C.; Adamson, A.; Daborn, G.; Houston, J.; Tootoo, V. Inuit Cyberspace: The Struggle for Access for Inuit Qaujimajatuqangit. J. Can. Stud./Rev. D'étud. Can. 2009, 43, 220-249. [CrossRef]

24. Roth, L. How Comfortably Does the Internet Sit on Canada's Tundra? Reflections on Public Access to the Information Highway in the North. In Cyberidentities: Canadian and European Presence in Cyberspace; d'Haenens, L., Ed.; University of Ottawa Press: Ottawa, ON, Canada, 1999; pp. 83-97.

25. Taylor, D.R.F. The concept of cybercartography. In Maps and the Internet; Peterson, M.P., Ed.; Elsevier: Amsterdam, The Netherlands, 2003; pp. 405-420.

26. Taylor, D.R.F. Some new applications in the theory and practice of cybercartography: Mapping with indigenous people in Canada's North. In Proceedings of the 24th International Cartographic Conference, Santiago, Chile, 15-21 November 2009.

27. Spencer, R.F. The North Alaskan Eskimo: A Study in Ecology and Society. Bur. Am. Ethnol. Bull. 1959, $171,1-237$.

28. Whitridge, P. Landscapes, Houses, Bodies, Things: "Place" and the Archaeology of Inuit Imaginaries. J. Archaeol. Method Theory 2004, 11, 213-250. [CrossRef]

29. Keith, D.; Crockatt, K.; Hayes, A. The Kitikmeot Place Name Atlas. In Developments in the Theory and Practice of Cybercartography; Taylor, D.R.F., Lauriault, T.P., Eds.; Elsevier Science: Amsterdam, The Netherlands, 2014; pp. 219-228.

30. Keith, D.; Griebel, B.; Gross, P.; Jorgensen, A.M. Digital Return of Inuit Ethnographic Collections using Nunaliit. In Further Developments in the Theory and Practice of Cybercartography: International Dimensions and Language Mapping; Taylor, D.R.F., Anonby, E., Murasugi, K., Eds.; Elsevier Press: Amsterdam, The Netherlands, 2019; pp. 297-316.

31. The Kitikmeot Place Name Atlas. Available online: https: / / atlas.kitikmeotheritage.ca/index.html (accessed on 31 March 2021).

32. Muller-Wille, L.; Weber, L. Inuit Place Name Inventory of Northeastern Quebec-Labrador; McGill Subarctic Research Paper; McGill University: Montréal, QC, Canada, 1983; Volume 37, pp. 151-222.

33. Dawson, P. 'Breaking the fourth wall': 3D virtual worlds as tools for knowledge repatriation in archaeology. J. Soc. Archaeol. 2011, 11, 387-402. [CrossRef]

34. Dawson, P.; Porter, C.; Gadbois, D.; Keith, D.; Hughes, C.; Suluk, L. Some Account of an Extraordinary Traveller. Étud. Inuit Stud. 2018, 42, 243-268. [CrossRef]

35. Mathiassen, T. Report of the Expedition; Gyldendalske Boghandel, Nodisk Forlag: Copenhagen, Denmark, $1945 ;$ Volume 1.

36. Rasmussen, K.; Den, V. Thule Ekspedition. Geogr. Tidsskr. 1921, Bind 26.

37. Rasmussen, K. Across Arctic America: Narrative of the Fifth Thule Expedition; Greenwood Publishers: New York, NY, USA, 1927. 
38. Rasmussen, K. Intellectual Culture of the Iglulik Eskimos; Gyldendalske Boghandel, Nodisk Forlag: Copenhagen, Denmark, 1929.

39. Griebel, B.; Keith, D.; Gross, P. Assessing the Significance of the Fifth Thule Expedition for Inuinnait and Inuit Knowledge. Alsk. J. Anthropol. 2021, 19, 1, 56-59.

40. Damas, D. Journey at the Threshold: Knud Rasmussen's Study of the Copper Eskimos, 1923-1924. Étud. Inuit Stud. 1988, $12,129-149$.

41. The Tumisiut Project. Available online: https://en.natmus.dk/historical-knowledge/research/research-projects/the-tumisiutproject/ (accessed on 31 March 2021).

42. The Fifth Thule Expedition Atlas. Available online: www.thuleatlas.org (accessed on 25 April 2021).

43. Aporta, C. From map to horizon; from trail to journey: Documenting Inuit geographic knowledge. Étud. Inuit Stud. 2005, 29, 221-231. [CrossRef]

44. PI/KHS. Inuinnait Songs \& Stories: Extracting Oral Traditions from An Ethnographic Source; A Downloadable PDF Version of the Book Is. Available online: www.kitikmeotheritage.ca/educational-resources (accessed on 13 May 2021).

45. The Inuinnait Knowledge Bank Prototype. Available online: https:/ /inuinnait.knowledgebank.ca (accessed on 24 May 2021).

46. Gadoua, M. Making Sense through Touch: Handling Collections with Inuit Elders and the McCord Museum. Senses Soc. 2014, 9, 323-341. [CrossRef]

47. Inuinnaqtun Documentation Tool Prototype. Available online: https://inuktutlexicon.gcrc.carleton.ca/index.html?module= module.inuktutlexicon_word_list_inuinnaqtun (accessed on 14 May 2021). 